\title{
Power consumption in the Eastern regions of Russia: prediction issues
}

Anatoliy Korneev*, and Konstantin Korneev, Melentiev Energy Systems Institute of Siberian Branch of the Russian Academy of Sciences, Irkutsk, Russia

\begin{abstract}
The paper deals with the economic development of Russia and its Eastern regions for a long-term horizon under periodically emerging crises. A macro-forecast of the economic development of Russia is offered and power consumption levels for the country and its Eastern regions are forecasted.
\end{abstract}

\section{Introduction}

Russia's Eastern regions - the Siberian Federal District (SFD) including the regions of East Siberia and the Far-Eastern Federal District (FEFD) with their arctic part - have a great potential for the resource and economic development, whose implementation in the long term may lead to a considerable increase in the regional power demand. In this context, the substantiated forecasts of regional economic development and power demand (power consumption) to be made remain a topical task to arrange power supply to users.

Monitoring the existing forecasts of power consumption in the country and its Eastern regions within the elaborated strategic documents has showed a significant discrepancy between the forecasted and real indicators. For example, according to the General Scheme of the power industry development until 2020 approved in February 2008 [1], Russia's power consumption in 2015 had to be 1426-1600 billion $\mathrm{kWh}$ from the base and maximum scenarios, but virtually it did not exceed 1060.2 billion $\mathrm{kWh}$, which is by $26-34 \%$ below the forecasted indicators. In 2020, the actual power consumption in the country will be about 1105 billion $\mathrm{kWh}$ in comparison with the forecasted value of 1710-2000 billion $\mathrm{kWh}$ according to the General Scheme, which is by $36-45 \%$ below the forecast. For the FEFD the forecast error is at a level of $18-40 \%$.

Depending on the time at which the forecast is made, the power consumption level for a longer term was also essentially corrected. Whereas according to the forecast made in 2008 within the Energy Strategy of Russia until 2030 [2], the power consumption in Russia in 2030 had be 1740-2164 billion $\mathrm{kWh}$, in 2015 it was forecasted at a level of 1292-1352 billion $\mathrm{kWh}$ for the same year, i.e. 448-812 billion $\mathrm{kWh}(26-38 \%)$ lower. The power consumption forecasts for East Siberia and the Far East were corrected at about the same percentage level.

A high variability of the forecasted indicators of power consumption and their susceptibility to practically annual corrections are indicative of the need to improve the

\footnotetext{
* Corresponding author: korn@isem.irk.ru
} 
forecasting methods in terms of their better adaptation to market and (as a rule) unstable conditions of the economy development.

\section{Main factors of the "short-term life" of the forecasted power consumption levels}

The forecasting practice shows that the "short-term life" of the forecasted power consumption levels is explained by various factors, the economic ones being predominant:

1. Overestimated "expectations and targets" of the economic development of the country and its regions by the federal and regional authorities in elaborated strategic documents, which leads to systematic correction of the forecasted economic growth rates.

2. Negative effect of the financial and economic crises in the world and in the country on the economy (decline in investment and economic activities).

3. Geopolitical challenges plus financial and economic sanctions of some developed countries against Russia.

4. Consideration of investment projects with a low feasibility level (inefficiency of projects, uncertainty of product markets, lack of investors, etc.) in the forecasts.

5. Insufficiently effective state financial- economic and investment policy, etc.

Forecasting the economy and energy development in the country and its regions in a market environment in combination with the internal and external factors is a difficult complex task. Different research institutions pay great attention to improvement of the methods and models in this area of forecasting. In particular, the Energy Research Institute of the Russian Academy of Sciences (ERI RAS) [3, 4], Melentiev Energy Systems Institute SB RAS (ESI SB RAS) [5, 6], and some others offer interesting methodological approaches to forecasting. However, the effect of limited investment in the basic assets, and the periodic actions of financial and economic crises on long-term forecasts have remained insufficiently considered in practice.

\section{Relation between investment in basic assets and economic growth}

Investment in the basic assets is formed from two sources: internal and outside funds, with the latter being more than $50 \%$ of the total investment (Table 1).

Table 1. Investment into the basic assets of Russia over 2000-2015 (in the 2000 prices)

\begin{tabular}{|l|c|c|c|c|c|c|c|c|c|}
\hline \multirow{2}{*}{ Investment source } & 2000 & 2005 & 2010 & 2015 & 2000 & 2005 & 2010 & 2015 \\
\cline { 2 - 10 } & \multicolumn{6}{|c|}{ Bln. rub. } & \multicolumn{5}{|c|}{$\%$} \\
\hline $\begin{array}{l}\text { Investment*, in } \\
\text { total, including: }\end{array}$ & 1055 & 1690 & 2369 & 2552 & 100 & 100 & 100 & 100 \\
\hline Internal funds & 501 & 752 & 971 & 1280 & 47,5 & 44,5 & 41,0 & 50,2 \\
\hline $\begin{array}{l}\text { Outside funds, } \\
\text { including: }\end{array}$ & 553 & 938 & 1398 & 1272 & 52,4 & 55,5 & 59,0 & 49,8 \\
\hline $\begin{array}{l}\text { Loans from } \\
\text { Russian banks }\end{array}$ & 25 & 122 & 159 & 164 & 2,4 & 7,2 & 6,7 & 6,4 \\
\hline Budgetary funds & 282 & 353 & 469 & 475 & 26,7 & 20,9 & 19,8 & 18,6 \\
\hline Foreign loans & 171 & 363 & 573 & 380 & 16,2 & 21,5 & 24,2 & 14,9 \\
\hline Other funds & 76 & 100 & 197 & 253 & 7,2 & 5,9 & 8,3 & 9,9 \\
\hline $\begin{array}{l}\text { Annual investment } \\
\text { indices, \% }\end{array}$ & & 110 & 107 & 101,5 & & & & \\
\hline $\begin{array}{l}\text { Annual GRP } \\
\text { indices, \% }\end{array}$ & 106,8 & 103,7 & 101,4 & & & & \\
\hline
\end{tabular}


Over the recent years, against various financial and economic sanctions, the share of the outside funds decreased and was $49.8 \%$ in 2015 , which is by $8.2 \%$ lower than in 2010 . This fact is basically related to a decrease in the share of foreign loans and budgetary funds of the Russian Federation. The crisis and sanction factors led to a decrease in the annual average investment indices from $110 \%$ in $2000-2005$ to $101.5 \%$ in $2010-2015$, which directly led to a decrease in the annual average GRP indices over the same periods from $106.8 \%$ to $101.4 \%$. The analysis of the investment and GRP dynamics over a longer retrospective interval (1995 through 2016) also shows a close dependence of the GRP production on investment, and it is especially explicitly seen in the crisis years: 1998, 2009, and in 2015-2016 (Fig. 1).

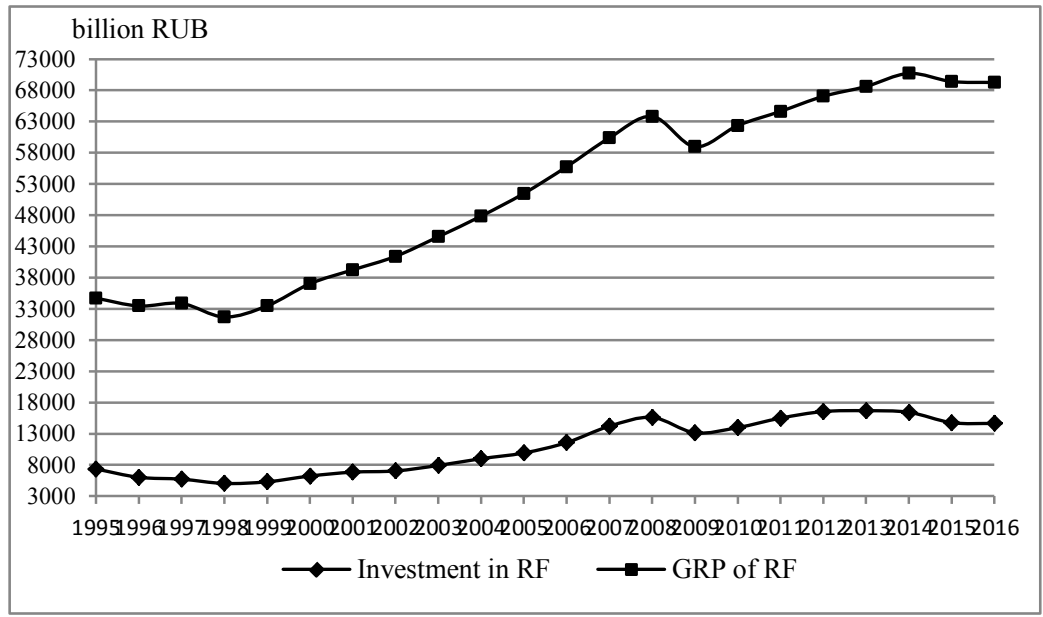

Fig. 1. Retrospective dynamics of the GRP and investment in the basic assets of RF

At the present stage, the increasing collisions of interstate interests in commercial, financial, political, and other areas create a favorable environment for periodic crises. Leading western and domestic economists, as well as analysts of the World Bank and the IMF note a persistent regularity of crises every 7-10 years, during which the economic growth rates and the investment fall dramatically [7, 8]. For example, in 1982, 1991, 19981999 , and 2009 , the economic growth rates decreased from $103-105 \%$ per year to $80-90 \%$ in the developed countries, and even more in the developing ones. Obviously, this factor cannot be ignored at a long-term economic forecasting, and especially for 20 and more years, which is proved by the present-day domestic long-term forecasts of the economy and energy development.

\section{Forecast of economic development and power consumption in Russia and its Eastern regions in the long term by the "crisis" scenario}

The starting points to forecast the economic development and power consumption in Russia and its Eastern regions by the "crisis" scenario are the following:

1. The forecasting period is until 2050, the initial year of forecasting being 2015 .

2. Russia's economy is presented in the aggregated form as GRP production and total investment in the basic assets. 
3. Throughout the 32-year forecast period, three crises are supposed to affect the economy development.

4. The growth rates of investment in the basic assets that are limitations for the GRP growth rate of the country are specified in accordance with the crisis periods (Fig. 2).

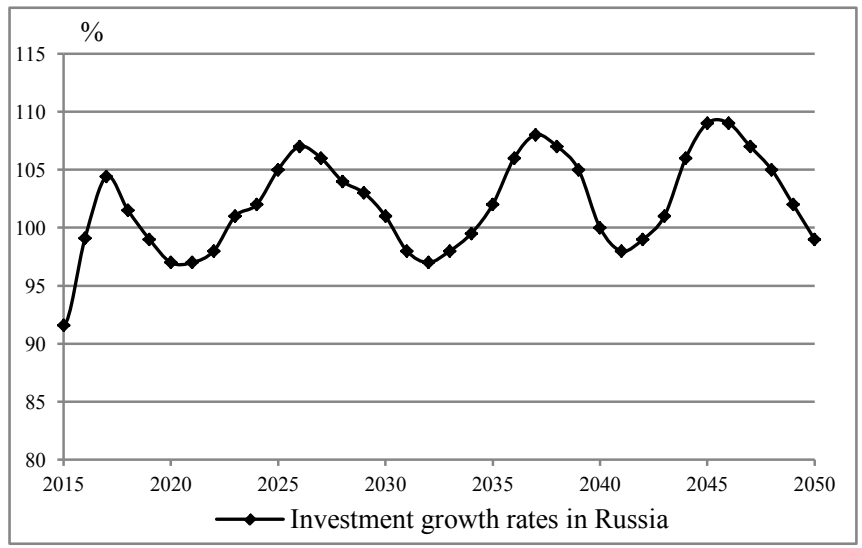

Fig. 2. Investment growth rates in Russia with periodic crises in the long term

The volume of investment is calculated on the basis of the investment growth rates, and the prospective GRP indicators in the country are determined through the investment return coefficients obtained from the retrospective data as a GRP-investment ratio. The 20002016 investment return coefficients had a relatively small scatter, and the GRP production was calculated by their mean value. The existing stable retrospective GRP structure in the country for the federal districts allows us to obtain the prospective GRP indicators for the SFD, for the regions of East Siberia, and for the FEFD by their shares in the country's GRP (a detailed calculation scheme is presented in [9]). In the context of the state objective of accelerated development of the Eastern regions, their shares in the GRP production were corrected toward an increase, and for the entire period (until 2050), they increase approximately by $0.5-1.0 \%$. Figs. 3-4 present the prospective GRP dynamics for the country and its regions.

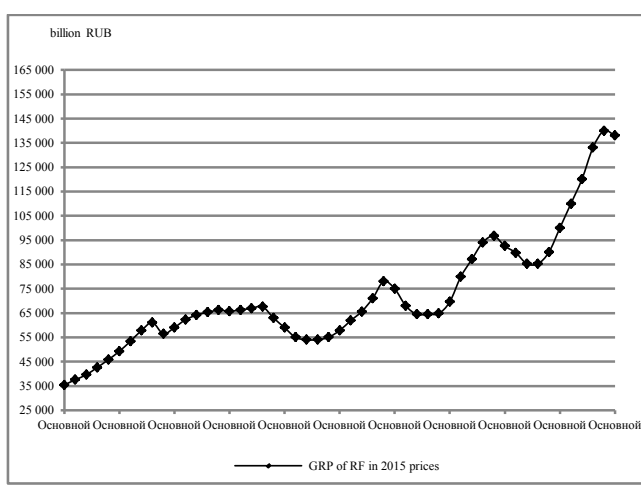

Fig. 3. Forecast of the GRP for the country

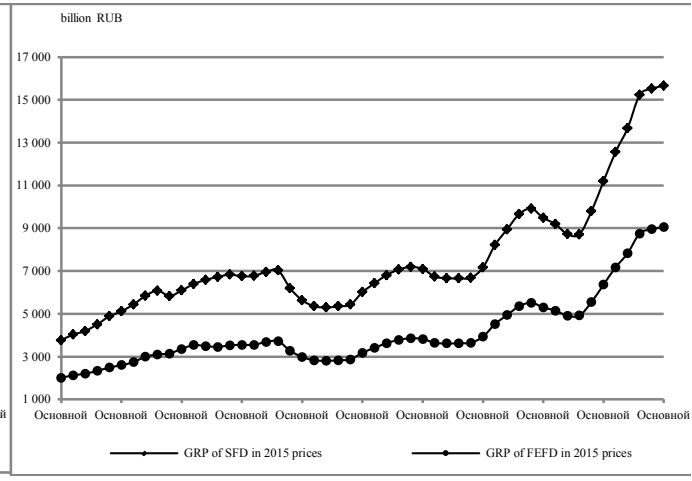

Fig. 4. Forecast of the GRP production for the Eastern regions 
The prospective power consumption indicators for the country are generally assessed by the specified dynamics of the GRP-power consumption ratio, considering the retrospective and prospective trends of its variation affected by the crises (Fig. 5).

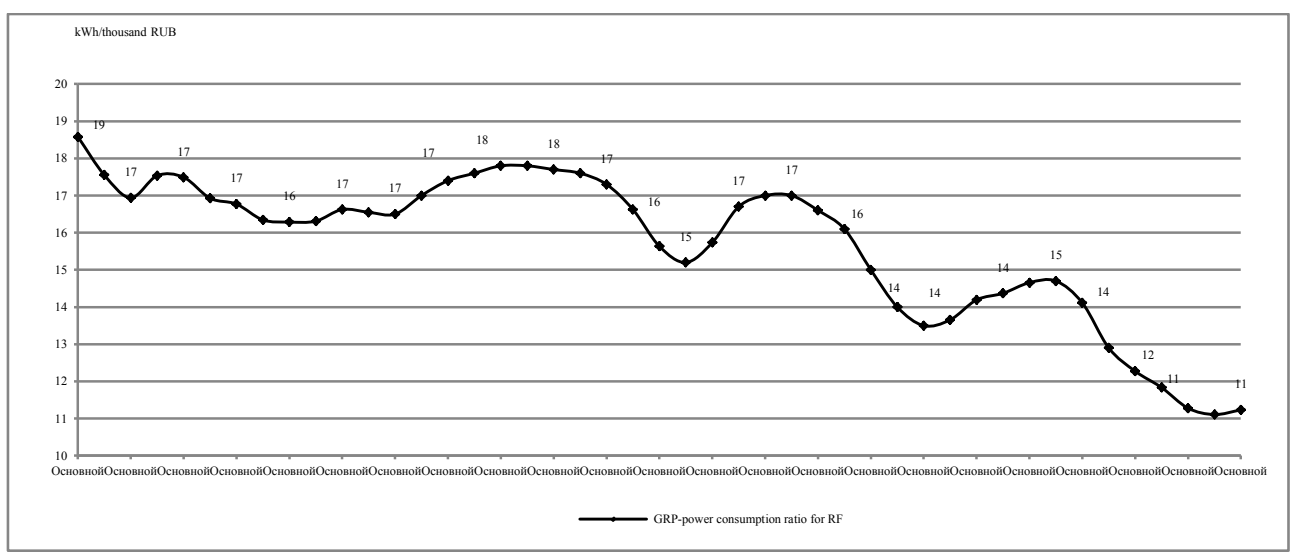

Fig. 5. Forecasted GRP-power consumption ratio for the Russian Federation by the "crisis" scenario

The Figure shows that at a general trend of decrease in the GRP-power consumption ratio in the country, it can increase during crises, depending on the GRP level and its structure. Moreover, the effects of various power saving technologies are supposed to be taken into consideration in the used indicators of GRP-power consumption ratio. The average annual rate of decrease in the GRP-power consumption ratio will be $1.3 \%$ over 2015-2050, whereas, it was $2.7 \%$ over $2000-2015$. The economic development instability and limited investment resources in the innovative renewal of the basic assts in the country will be the major factors restraining the decrease in GRP-power consumption ratio in the "crisis" scenario in the long term.

The forecasted power consumption level in the country by the "crisis" scenario may be about 1550 billion kWh by 2050, and may increase by factor of 1.5 as compared with 2015 (Fig. 6).

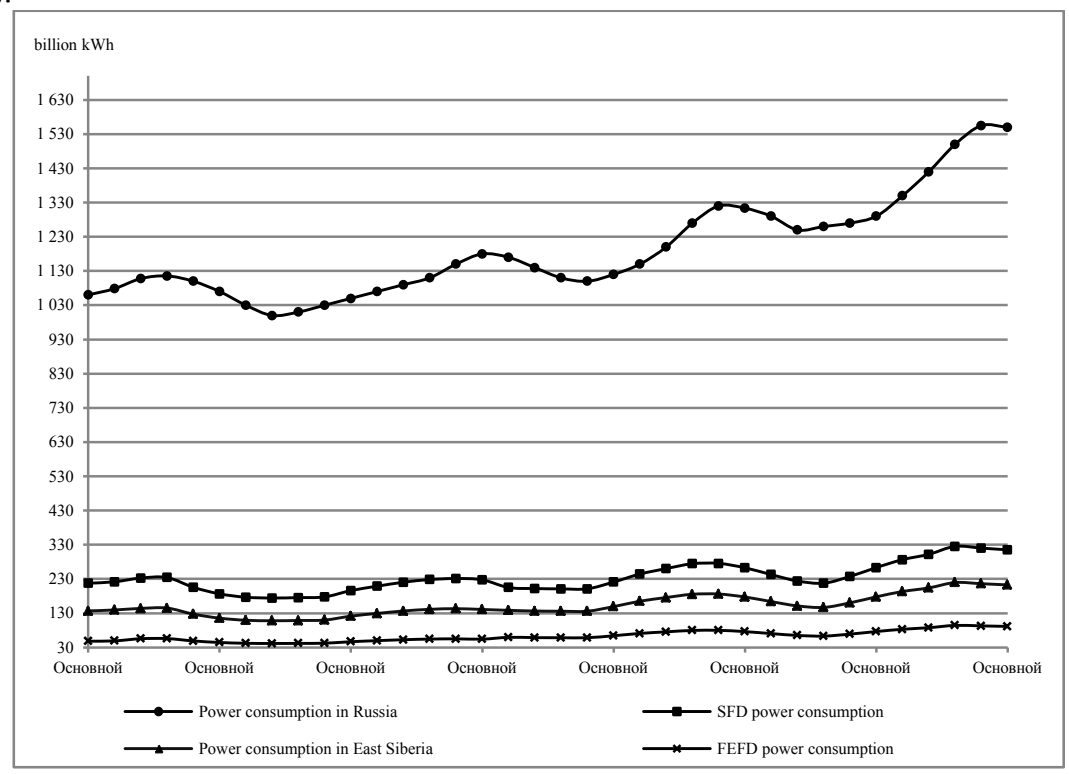

Fig. 6. Forecasted dynamics of power consumption in Russia and its Eastern regions 
The power consumption in the SFD will be 315 billion $\mathrm{kWh}$ in 2050, which is by factor of 1.5 above the 2015 level, 90 billion kWh in the FEFD (by factor of 1.8), and 215 billion $\mathrm{kWh}$ in the regions of East Siberia (by factor of 1.6). By 2050, the total share of the Eastern regions in the power consumption in the country will not practically change relative to 2015 , and will remain at $26.2 \%$. But in the FEFD it will increase by $1.3 \%$ and will make up 5.8\%, in the regions of East Siberia - by 1.0\% making up $13.9 \%$.

The obtained levels of the power consumption in the country and its Eastern regions in the long term by the "crisis" scenario differ considerably from the forecast in the draft of the Energy Strategy until 2035 that was made in 2017 [10]. The power consumption indicators by the "crisis" scenario are lower: for Russia - by 100 billion kWh in 2030, and by 150 billion $\mathrm{kWh}$ in 2035 . The power consumption levels for Russia and its Eastern regions according to the draft of the Energy Strategy until 2035 will be reached in the "crisis" scenario as early as 2043 (Table 2).

Table 2. Forecasts of the power consumption in Russia and its Eastern regions according to the draft of the Energy Strategy until 2035, and by the "crisis" scenario until 2050*, billion kWh

\begin{tabular}{|l|c|c|c|c|c|}
\hline \multirow{2}{*}{ Region } & \multicolumn{5}{c|}{ Year } \\
\cline { 2 - 6 } & 2030 & 2035 & 2040 & 2045 & 2050 \\
\hline Russia & $1180 / 1280$ & $1230 / 1370$ & $1320 /-$ & $1400 /-$ & $1550 /-$ \\
\hline Siberian Federal District & $230 / 260$ & $240 / 270$ & $260 /-$ & $280 /-$ & $310 /-$ \\
\hline East Siberia & $145 / 167$ & $155 / 180$ & $175 /-$ & $190 /-$ & $210 /-$ \\
\hline $\begin{array}{l}\text { Far-Eastern Federal } \\
\text { District }\end{array}$ & $63 / 55$ & $60 / 72$ & $68 /-$ & $78 /-$ & $90 /-$ \\
\hline
\end{tabular}

*The numerator shows the prediction metrics from the crisis scenario, the denominator presents the same from the Project of the Power Strategy

Presently, the Energy Strategy of Russia until 2035 has been under development, and the main condition of its completion is to elaborate a state economic policy for a long-term horizon. In accordance with it, a new Strategy of Social and Economic Development of Russia, considering various scenarios of the new internal and external conditions as well as the crisis ones at the current stage will be elaborated and approved.

\section{Conclusions}

The macro-forecast of the power consumption in Russia and its Eastern regions by the "crisis" scenario does not exclude consideration of other scenarios, optimistic or pessimistic. It can be used as a starting point for elaboration of state and non-state strategies and programs for the energy sector development in the country and the federal districts on a long-term horizon.

The used methodological and calculation schemes to forecast the economy development and power consumption is applicable mainly to macro-regions at the levels of the country and the federal districts. The economy development and power consumption at the level of Russian Federation Entities or their intraregional and interregional territories (for example, northern territories, arctic zones, territorial and production complexes, etc.) can be forecasted based on the detailed consideration of the productive forces of the given territories and the "points" of economic growth in relation to priority basic projects. Besides, as a rule, the forecasting period which does not exceed 15 years and possesses a sufficiently high certainty of the future is the most effective for such territorial entities. 


\section{Acknowledgements}

The study was carried out within the scientific project III.17.6.1. of the fundamental research program of SB RAS of the Russian Academy of Sciences, reg. No. AAAA-A17$117030310445-9$

\section{References}

1. The 2008 February 22 General Scheme No.215-p for allocation of electric power industry objects until 2020 (Application, p. 17). [e-resource]. - Access mode: https://zakonbase.ru/content/part/572036 (Address date: 05 April 2018), in Russian.

2. State Information System in power saving // 2030 Power Strategy of Russia. [eresource]. - Access mode: <https://gisee.ru/law/others/46961/> - (Address date: 05 April 2018) (in Russian)

3. A.A. Makarov. System analysis of power engineering perspectives. Izvestiya RAN (Proceedings of the Russian Academy of Sciences). Energy Ser., No. 4, (2010) (in Russian)

4. S.P. Fillippov. Predicting the power consumption by using the complex of adaptive imitative models. Izvestiya RAN (Proceedings of the Russian Academy of Sciences). Energy Ser., No. 1 (2003) (in Russian)

5. Yu.D. Kononov et al. ol. Methods and models for prediction research into interconnections between power engineering and economy. Novosibirsk: Nauka (Science) Publishers, 178 p. (2009) (in Russian)

6. Methods and models for developing regional power programs / Ed. by B.G. Saneev. Novosibirsk: Nauka (Science) Siberian Publishing Firm of RAS, 170 p. (2002) (in Russian)

7. Cyclicity of the present-day economy development. Problem of recession in Russia. Access mode: <https://otherreferats.allbest.ru/economy/00786490_0.html> - Address date: 05 April 2018 (in Russian)

8. Juglar cycles. [e-resource]. - Access mode: <https://ru.wikipedia.org/wiki/> - (Address date: 05 April 2018) (in Russian)

9. A.G. Korneev, G.V. Agafonov, and A.S. Tsapakh. Methodical approaches to longterm prediction of the power consumption in Russia's eastern regions. Miscellany from the All-Russia Conference (Melentiev Energy Systems Institute SB RAS, 1-3 September 2015) «Power engineering of Russia in the $21^{\text {st }}$ Century. Innovative development and management». Irkutsk, (14 November 2015, e-version) (in Russian)

10. Project of the Russian Federation Power Strategy until 2035 (The 01 February 2017 edition). [e-resource]. URL: <https://minenergo.gov.ru/node/1920> (Address date: 28 June 2018) (in Russian) 